\title{
Distributed study facilitates infants' delayed recognition memory
}

\author{
EDWARD H. CORNELL \\ University of Alberta, Edmonton, Alberta T6G 2E9, Canada
}

\begin{abstract}
Infants of 5-6 months of age were tested for recognition of briefly presented photographs of faces. The interaction typically obtained with adults, a beneficial effect on retention due to the temporal spacing of study, was obtained with these infants. The results suggest that the distribution effect reflects a fundamental and automatic process of human memory.
\end{abstract}

When two pictures appear side by side, young infants tend to look at a novel picture more than a previously exposed picture (Cohen \& Gelber, 1975; Fagan, 1975; Olson, 1976). This selective attention indicates recognition; the previously exposed picture is less attractive because it is familiar. The present study indicates that such familiarity lasts for longer durations following distributed exposures than following massed exposures.

These results affirm that the so-called distribution effect is ubiquitous in studies of memory for individual items. The distribution effect refers to the basic observation that performance is better when repetitions of an item are separated by time (or other items) than when these repetitions occur one immediately after the other (Crowder, 1976). The distribution effect is present in Ebbinghaus' (1885/1964) classic data and occurs in a variety of tasks with different materials to be remembered and different indexes of retention (Hintzman, 1974, 1976). A complete theory of human memory processes must explain the distribution effect, and there have been several attempts to do so. Some of these theories emphasize that unconscious, incidental, or automatic processes lead to the distribution effect, whereas others emphasize that voluntary, deliberate, strategic, or semantic cognition is involved (Hintzman, 1974, 1976). The former emphases may be more attractive than the latter in light of the infant's capabilities.

The effects of distributed study also have implications for recent attempts to describe how learning and memory may be facilitated in early infancy (Fagan, 1978; Ruff, 1978). For example, in the study of infants' visual habituation, the separate familiarization exposures usually occur one immediately after the other. One early emphasis was to establish that infants do, in fact, habituate to visual patterns (e.g., Fantz, 1964; Pancratz \&

This research was supported by Grant A0267 from the Natural Sciences and Engineering Research Council of Canada. I thank Linda Bergstrom, Philomena MacKenzie, Dawn Ringrose, and several colleagues who commented on the paper. Requests for reprints should be addressed to Edward H. Cornell, Department of Psychology, University of Alberta, Edmonton, Alberta T6G 2E9, Canada.
Cohen, 1970). It was thought that repetitions should be arranged in close succession to prevent any loss of memory from one exposure to the next (Jeffrey \& Cohen, 1971). This assumption may be correct if one is testing for short-term retention; however, animal studies have indicated more long-term retention under conditions of long rather than short interstimulus intervals (Davis, 1970; Leaton, 1976; Wagner, 1976). Since it seemed desirable to establish a variety of learning conditions that facilitate infants' memory, the procedures used in the present experiment varied the temporal distribution of study periods and tested both immediate and delayed retention.

\section{METHOD}

\section{Subjects}

One hundred and fifteen full-term healthy babies were tested in their homes. Their names were obtained from birth announcements published in the local newspaper. Parents were sent a form letter describing the purposes, procedures, and sponsorship of the study and were subsequently contacted by phone to discuss the study and to schedule appointments. As it turned out, all of the babies were Caucasian and resided in middle-class or upper middle-class neighborhoods. The data obtained from 19 babies were replaced, 5 as a consequence of experimenter errors, 6 because of equipment failure, and 8 because of the infants' fussiness or lack of interest throughout the tests. All infants were between 22 and 27 weeks of age (median $=24$ weeks). There were equal numbers of boys and girls assigned to all subgroups within the study.

\section{Apparatus and Materials}

A portable visual preference apparatus was assembled in the living room. The details of the apparatus are described by Fantz and Nevis (1967), and there is a photograph of it in Miranda (1970). The essential features include (1) a box with homogeneous interior walls to contain the field of vision of the baby, (2) a stage-like platform at the back of the interior, which supported two stimulus targets and rotated out of the interior so that the stimuli could be changed in $3-5 \mathrm{sec}$, and (3) a peephole centered on the stage so that an observer could clearly see the baby's eyes from a distance of approximately $35 \mathrm{~cm}$. The interior walls of the box were lined with gray felt, which absorbed light, and the stimulus targets were semiglossy and reflected light. This arrangement produced a small reflection of the stimulus that was fixated superimposed over the center of the baby's pupil. The fixation response is schematically illustrated 
by Fantz (1966). A second peephole, located at the top of the interior, was used with a mirror to allow a second observer to see fixations from the same perspective as the principal observer. A four-channel Rustrak event recorder was attached to the exterior of the box and was wired to electronic timers and switches used by the observers to monitor fixations to the left or right stimulus targets.

The stimuli were cutouts of black-and-white photographs of faces mounted on white Bristol board. There were photographs of two adult males and two adult females, similar to the frontal poses illustrated in Cornell (1974). The faces measured approximately $14 \mathrm{~cm}$ from chin to hairline, and the background was $18 \times 15 \mathrm{~cm}$.

\section{Procedure}

Infants' recognition memory was tested with a variation of a procedure developed by Fagan (1970). Each infant was given two recognition problems, each consisting of a familiarization exposure, a retention interval, and a recognition test. The recognition problems differed as to the stimuli to be remembered and the familiarization procedure used. Each infant received two familiarization procedures. Although in both procedures an infant looked at a pair of identical photos for a total of $20 \mathrm{sec}$, in one procedure (massed) the four study periods occurred $3 \mathrm{sec}$ apart, and in the other procedure (distributed) they were spaced at 1-min intervals. A study period was of variable duration; the photos were withdrawn for the interstudy interval after the experimenter had recorded $5 \mathrm{sec}$ of accumulated looking.

An infant was randomly assigned to receive either massed or distributed familiarization first. In the distributed procedure, the visual preference apparatus was pulled away from the baby immediately after the photos were withdrawn for the interstudy interval. This prevented the baby's becoming restless in the homogeneous interior of the apparatus. For $1 \mathrm{~min}$, the baby was free to look around the room; then the apparatus was repositioned and the photos were reexposed. An attempt was made to equate the massed procedure for the movements of the apparatus and the duration of the familiarization phase that occurred in the distributed procedure. Before the onset of massed study, the empty afparatus was positioned and then withdrawn for $1 \mathrm{~min}$. These movements and delays were repeated three times, and immediately after the apparatus surrounded the baby for the fourth time, the experimenter presented the photo for massed study.

A retention interval followed the fourth study period. Twenty-four infants were assigned to one of four retention intervals: $5 \mathrm{sec}, 1 \mathrm{~min}, 5 \mathrm{~min}$, and $1 \mathrm{~h}$. A baby experienced the same retention interval for both massed and distributed procedures. The apparatus was quickly withdrawn and repositioned to constitute the 5 -sec retention interval. A similar procedure was used during the 1- and 5-min delays; the baby remained on the mother's lap while outside the apparatus. The experimenters left the house during the $1-\mathrm{h}$ retention intervals, and the mother and baby went about their normal activities.

A short recognition test followed the retention interval. The previously exposed photo was paired with a photo of the opposite sex for $5 \mathrm{sec}$. The two photos were then withdrawn for $3 \mathrm{sec}$, their left-right positions were interchanged, and they were presented for another $5 \mathrm{sec}$. This transposition was to counteract any tendencies to gaze at a particular photo location. Following the recognition test, the apparatus was withdrawn for a 1-min break between the massed and distributed procedures.

Each infant was familiarized with photos of one sex. For example, if a male face served as the photo to be remembered in the first procedure, a different male face served this role in the second procedure. Each infant also saw two different novel faces during the recognition tests. To continue the preceding example, following study of the first male face, it would be paired with a female face, and following study of the second male face, it would be paired with another female face. Pilot testing indicated that the photos yielded approximately equal initial attention. In addition, each photo served equally often as novel and familiar in both massed and distributed procedures.

Looking behavior was recorded by observers who were experienced with the apparatus but were not informed of the exact purposes of the study. To provide a check on the reliability of measurement of the fixation responses, both observers monitored the responses made by 12 infants during the recognition test that followed $1 \mathrm{~h}$ after the familiarization procedures.

\section{RESULTS}

The two observers were in good agreement on the simultaneous records; the Pearson coefficient of correlation between recorded fixation times was .94. This high degree of interobserver agreement is consistent with the findings of other studies using the same apparatus and measurement procedures (Cornell, 1974, 1979).

Table 1 indicates the infants' differential looking after each familiarization procedure and retention interval. The $p$ values noted are for a comparison of the $t$ values for differences between the percentage of total fixation to the novel photo and a chance value of $50 \%$. All $p$ values mark a significant tendency to look at the novel of the paired test photos, as indicated by twotailed tests.

The differential looking was examined in reference to three other factors: sex of the infant, order of the familiarization procedures, and photo used during familiarization. Analyses indicated that none of these factors significantly affected the test data. Hence, these factors were collapsed to test the distribution effect.

The test for the distribution effect involved two factors, retention interval (four treatments) and familiarization procedure (two treatments), with the latter being a within-subjects factor. A repeated-measures analysis of variance for the percentage fixation to the novel photo indicated a reliable main effect due to the familiarization procedure $[F(1,92)=7.9, \mathrm{p}<.01]$ and a reliable interaction between familiarization procedure and retention interval $[F(3,92)=2.7, p<.05]$.

A post hoc analysis examined three indexes of study

Table 1

Total Fixation Time (in Seconds) to Both Faces and Percentage Paid to Novel Face During Recognition Tests

\begin{tabular}{|c|c|c|c|c|c|}
\hline \multirow{2}{*}{$\begin{array}{c}\text { Proce- } \\
\text { dure }\end{array}$} & \multirow{2}{*}{$\begin{array}{l}\text { Retention } \\
\text { Interval }\end{array}$} & \multicolumn{2}{|c|}{ Total Fixation } & \multicolumn{2}{|c|}{ Novel Fixation } \\
\hline & & Mean & SD & Mean & SD \\
\hline M & $5 \mathrm{sec}$ & 6.3 & 2.7 & $66 *$ & 19 \\
\hline D & $5 \mathrm{sec}$ & 6.2 & 2.0 & $61 *$ & 18 \\
\hline M & $1 \mathrm{~min}$ & 7.4 & 1.8 & 47 & 20 \\
\hline $\mathrm{D}$ & $1 \mathrm{~min}$ & 7.1 & 1.9 & $61^{*}$ & 15 \\
\hline $\mathbf{M}$ & $5 \mathrm{~min}$ & 6.2 & 2.2 & 52 & 20 \\
\hline $\mathrm{D}$ & $5 \mathrm{~min}$ & 6.3 & 2.1 & $60^{*}$ & 15 \\
\hline $\mathbf{M}$ & $1 \mathrm{~h}$ & 6.9 & 2.5 & 53 & 15 \\
\hline D & $1 \mathrm{~h}$ & 6.8 & 2.4 & $62^{*}$ & 14 \\
\hline
\end{tabular}

Note-Each entry represents the mean value for 24 infants. "Procedure" refers to familiarization procedure: $M=$ massed; $D=$ distributed. $\quad * p<.01$. 
Table 2

Characteristics of Visual Study During Familiarization Exposures

\begin{tabular}{|c|c|c|c|c|c|c|c|c|c|}
\hline \multirow[b]{2}{*}{ Measure } & \multirow{2}{*}{$\begin{array}{c}\text { Familiarization } \\
\text { Procedure }\end{array}$} & \multicolumn{2}{|c|}{ Study Period 1} & \multicolumn{2}{|c|}{ Study Period 2} & \multicolumn{2}{|c|}{ Study Period 3} & \multicolumn{2}{|c|}{ Study Period 4} \\
\hline & & Mean & SD & Mean & SD & Mean & SD & Mean & SD \\
\hline Seconds of Exposure & $\begin{array}{l}M \\
D\end{array}$ & $\begin{array}{l}8.6 \\
9.3\end{array}$ & $\begin{array}{l}4.5 \\
5.9\end{array}$ & $\begin{array}{l}11.1 \\
10.4\end{array}$ & $\begin{array}{l}6.2 \\
6.2\end{array}$ & $\begin{array}{l}10.6 \\
10.7\end{array}$ & $\begin{array}{l}6.6 \\
6.3\end{array}$ & $\begin{array}{l}12.2 \\
11.4\end{array}$ & $\begin{array}{l}8.1 \\
6.8\end{array}$ \\
\hline Number of Fixations & $\begin{array}{l}M \\
D\end{array}$ & $\begin{array}{l}3.4 \\
3.3\end{array}$ & $\begin{array}{l}1.8 \\
1.9\end{array}$ & $\begin{array}{l}4.0 \\
3.9\end{array}$ & $\begin{array}{l}1.9 \\
1.8\end{array}$ & $\begin{array}{l}3.9 \\
4.1\end{array}$ & $\begin{array}{l}1.9 \\
1.9\end{array}$ & $\begin{array}{l}4.1 \\
4.3\end{array}$ & $\begin{array}{l}2.0 \\
1.9\end{array}$ \\
\hline Number of Shifts & $\begin{array}{l}\text { M } \\
\mathrm{D}\end{array}$ & $\begin{array}{l}1.7 \\
1.7\end{array}$ & $\begin{array}{l}1.5 \\
1.6\end{array}$ & $\begin{array}{l}2.0 \\
2.0\end{array}$ & $\begin{array}{l}1.4 \\
1.6\end{array}$ & $\begin{array}{l}1.8 \\
2.0\end{array}$ & $\begin{array}{l}1.5 \\
1.8\end{array}$ & $\begin{array}{l}2.0 \\
2.2\end{array}$ & $\begin{array}{l}1.6 \\
1.7\end{array}$ \\
\hline
\end{tabular}

Note-Each entry represents the mean value for 96 infants. Each infant accumulated 5 sec of on-target looking during each study period. $M=$ massed $D=$ distributed.

behaviors during familiarization: duration of exposure, number of fixations, and number of fixation shifts (Ruff, 1975). As can be seen in Table 2, there was no obvious difference between the patterns of behaviors that occurred during the massed and distributed study.

\section{DISCUSSION}

To summarize, infants who were tested immediately after either familiarization procedure tended to look more at a novel photo than at the photo they had just studied. When there was a more substantial delay between study and test, recognition was evident only following the more distributed study. This pattern of results is typical of the distribution effect.

This is a striking demonstration of the automaticity of early learning and memory. The babies learned as a natural concomitant of their visual interest in faces, and they showed that they remembered faces incidentally, during the course of other visual explorations. Furthermore, it appears that there are processes underlying the distribution effect that are spontaneous. It seems safe to assume the infants did not anticipate being tested for memory, and even if they did, it is doubtful they could initiate deliberate mnemonics. Thus, the mechanisms that produced the delayed retention were likely activated unconsciously.

This does not preclude the distribution effect being augmented by cognitive operations such as semantic encoding, rehearsal, or elaboration of items. These can be characterized as strategic control processes that are typically used by adults and older children when they attempt to remember items (Atkinson \& Shiffrin, 1968; Kail, 1979). But the present results indicate that such mnemonics are unnecessary to obtain the distribution effect, occurring, as it does, in the early months of life.

There are several theories that may account for distribution effects in infants' memory. Perhaps the most plausible at this time are encoding variability theories and inattention theories (Crowder, 1976). Encoding variability theories emphasize that an item is learned in a context, and presentations that are temporally spaced usually provide a number of different contextual associations. For example, in the present study, when the apparatus was withdrawn for an interstimulus interval, the baby was free to sample a variety of elements in the home surroundings. According to a derivation of Estes' $(1955,1959)$ stimulus fluctuation model, such sampling increases the probability that the item to be remembered will be associated with the context operating near the time of retrieval (Crowder, 1976). Thus, a photo that received distributed study was likely to have been associated with objects or events that immediately preceded the delayed recognition tests.

In addition, encoding variability theories generally define the cognitive or emotional state of the learner as a context, and this definition may be used to interpret the present data. We may assume that, even though the babies saw the photos presented in the same physical context, distributed study allowed for more variability in state than did massed study. Again, such variability may increase the probability that the states during familiarization and test will be similar, and this similarity should facilitate recognition. It would be possible to more directly test encoding variability theories with infants by inducing different states or by presenting items for familiarization in varied environmental contexts.

Inattention theories of the distribution effect emphasize that learning is somewhat inhibited when study is massed. The idea is that one or two exposures are sufficient to induce a short-term familiarity with an item, and this familiarity affects attention to closely succeeding exposures. The distribution effect does not occur because distributed study boosts memory performance, but because immediate repetitions of an item are not well attended. This interpretation is consistent with the pattern of performance indicated in Table 1 . Delayed recognition drops to chance levels following massed repetitions.

Inattention theories are also compatible with process models of infant and infrahuman habituation performance (Jeffrey, 1976; Wagner, 1978). For example, we may assume that after the initial exposure of an item, the baby has partially habituated to its most salient features. If a second study period immediately follows, the baby's pattern of attention may be different from 
what it would be if there had been time for recovery of the habituated response. The most obvious prediction from this interpretation is that the baby should show declining interest in the item across close successive presentations. Yet the data from the present study belie this prediction. The visual behaviors and exposure times reported in Table 2 indicate approximately the same patterns of attention across both massed and distributed procedures. However, it is possible that the brief exposures of photos of faces resulted in ceiling effects in the present measures of attention. It may be more revealing to test the inattention theory with simple stimuli that allow for assessment of memory for specific constituent dimensions.

The preceding discussion suggests that the study of preverbal infants may provide unique tests of process theories. There may also be intriguing implications for general theories of human memory development. If we assume developmental continuity, the same memory processes operating in infancy would operate in adulthood. If we make the opposite assumption, developmental discontinuity, the early mechanisms of memory are supplanted by presumably more strategic ones. An intermediate viewpoint is that deliberate adult strategies may reinstate or maintain the more automatic processes of memory in the infant. The present results support the parsimonious argument that at least the basic processes of recognition memory are the same throughout the life span (Bahrick, Bahrick, \& Wittlinger, 1975; Brown, 1973, 1975; Mandler \& Robinson, 1978; Olson, 1976).

\section{REFERENCES}

Atkinson, R. C., \& Shiffrin, R. M. Human memory: A proposed system and its control processes. In K. W. Spence \& J. T. Spence (Eds.), The psychology of learning and motivation (Vol. 2). New York: Academic Press, 1968.

Bahrick, H. P., Bahrick, P. O., \& Wittlinger, R. P. Fifty years of memory for names and faces: A cross-sectional approach. Journal of Experimental Psychology: General, 1975, 104, 54-75.

Brown, A. L. Judgments of recency for long sequences of pictures: The absence of a developmental trend. Journal of Experimental Child Psychology, 1973, 15, 473-481.

Brown, A. L. The development of memory: Knowing, knowing about knowing, and knowing how to know. In H. Reese (Ed.), Advances in child development and behavior (Vol. 10). New York: Academic Press, 1975.

Cohen, L. B., \& Gelber, E. R. Infant visual memory. In L. Cohen \& P. Salapatek (Eds.), Infant perception: From sensation to cognition (Vol. 1). New York: Academic Press, 1975.

CORNELL, E. H. Infants' discrimination of photographs of faces following redundant presentations. Journal of Experimental Child Psychology, 1974, 18, 98-106.

Cornell, E. H. Infants' recognition memory, forgetting, and savings. Journal of Experimental Child Psychology, 1979, 28, 359-374.

Crowder, R. G. Principles of learning and memory. Hillsdale, N.J: Erlbaum, 1976.

Davis, M. Effects of interstimulus interval length and variability on startle-response habituation in the rat. Journal of Comparative and Physiological Psychology, 1970, 72, 177-192.

Ebbinghaus, H. E. Memory: A contribution to experimental psychology. New York: Dover, 1964. (Originally published 1885.)
Estes, W. K. Statistical theory of spontaneous recovery and regression. Psychological Review, 1955, 62, 145-154.

EsTES, W. K. The statistical approach to learning theory. In S. Koch (Ed.), Psychology: A study of a science (Vol. 2). New York: McGraw-Hill, 1959.

FAGAN, J. F. Memory in the infant. Journal of Experimental Child Psychology, 1970, 9, 217-226.

F AGAN, J. F. Infant recognition memory as a present and future index of cognitive abilities. In N. Ellis (Ed.), Aberrant development in infancy: Human and animal studies. Hillsdale, N.J: Erlbaum, 1975.

Fagan, J. F. Facilitation of infants' recognition memory. Child Development, 1978, 49, 1066-1075.

FANTZ, R. L. Visual experience in infants: Decreased attention to familiar patterns relative to novel ones. Science, 1964, 146, 668-670.

FANTz, R. L. Pattern discrimination and selective attention as determinants of perceptual development from birth. In A. Kidd \& J. Rivoire (Eds.), Perceptual development in children. New York: International Universities Press, 1966.

FANTZ, R. L., \& Nevis, S. The predictive value of changes in visual preferences in early infancy. In J. Hellmuth (Ed.), The exceptional infant (Vol. 1). Seattle: Straub \& Hellmuth, 1967.

Hintzman, D. L. Theoretical implications of the spacing effect. In R. Solso (Ed.), Theories in cognitive psychology: The Loyola symposium. Potomac, Md: Erlbaum, 1974.

Hintzman, D. L. Repetition and memory. In G. Bower (Ed.), The psychology of learning and motivation (Vol. 3). New York: Academic Press, 1976.

JefrReY, W. E. Habituation as a mechanism for perceptual development. In T. J. Tighe \& R. N. Leaton (Eds.), Habituation: Perspectives from child development, animal behavior, and neurophysiology. Hillsdale, N.J: Erlbaum, 1976.

JefFrey, W. E., \& Cohen, L. B. Habituation in the human infant. In $\mathrm{H}$. Reese (Ed.), Advances in child development and behavior (Vol. 6). New York: Academic Press, 1971.

KaIL, R. The development of memory in children. San Francisco: Freeman, 1979.

LEATON, R. N. Long-term retention of the habituation of lick suppression and startle response produced by a single auditory stimulus. Journal of Experimental Psychology: Animal Behavior Processes, 1976, 2, 248-259.

Mandlek, J. M., \& Robinson, C. A. Developmental changes in picture recognition. Journal of Experimental Child Psychology, 1978, 26, 122-136.

Miranda, S. B. Visual abilities and pattern preferences of premature infants and full-term neonates. Journal of Experimental Child Psychology, 1970, 10, 189-205.

Otson, G. M. An information processing analysis of visual memory and habituation in infants. In T. Tighe \& R. Leaton (Eds.), Habituation: Perspectives from child development, animal behavior, and neurophysiology. Hillsdale, N.J: Erlbaum, 1976.

Pancratz, C. N., \& Cohen, L. B. Recovery of habituation in infants. Journal of Experimental Child Psychology, 1970, 9, 208-216.

RuFf, H. A. The function of shifting fixations in the visual perception of infants. Child Development, 1975, 46, 857-865.

RuFF, H. A. Infant recognition of the invariant form of objects. Child Development, 1978, 49, 293-306.

Wagner, A. R. Priming in STM: An information-processing mechanism for self-generated or retrieval-generated depression in performance. In T. Tighe \& R. Leaton (Eds.), Habituation: Perspectives from child development, animal behavior, and neurophysiology. Hillsdale, N.J: Erlbaum, 1976.

WAGNER, A. R. Expectancies and the priming of STM. In S. H. Hulse, H. Fowler, \& W. K. Honig (Eds.), Cognitive processes in animal behavior. Hillsdale, N.J: Erlbaum, 1978.

(Received for publication January 22, 1980; revision accepted May 21, 1980.) 